\title{
PARTIAL UNDERCUTTING FACETECTOMY FOR BONY ENTRAPMENT OF THE LUMBAR NERVE ROOT
}

\author{
C. J. M. GETTY, J. R. JOHNSON, E. O'G. KIRWAN, M. F. SULLIVAN
}

From the Problem Back Unit, Royal National Orthopaedic Hospital, London

\begin{abstract}
Seventy-eight patients who had been operated on for bony entrapment of lumbar nerve roots were studied in an attempt to define the clinical syndrome, and to assess the results of a new technique of decompression which preserves spinal stability. The mean age of the patients was 45 years and 28 of them had previously undergone spinal operations. Pain in the leg was the predominant symptom, with evidence of motor involvement in half of the patients. Signs of nerve root tension were found in only one-third of the patients. The principal factor in the aetiology was degenerative change in the posterior facet joints. Decompression was achieved by a partial undercutting facetectomy. Fifty-nine per cent of the patients obtained a "good" result and 85 per cent were satisfied with the result of their operation. Successful partial facetectomy for bony entrapment of lumbar nerve roots produced rapid and lasting relief of pain.
\end{abstract}

In 1934 Mixter and Barr introduced the concept of prolapse of the intervertebral disc as a cause of low back pain and sciatica. Since then the "disc" has tended to dominate the surgical approach to these symptoms. Putti (1927) first drew attention to the importance of the posterior facet joints, stating that "sciatica is a neuralgia caused by pathological conditions of the intervertebral foramina and especially of the intervertebral articulations". He emphasised that the primary pathological change was "arthritis". Several authors report lumbar nerve root entrapment in the lateral recess of a spinal canal of normal dimensions (Epstein $e t$ al. 1972; Choudhury and Taylor 1977). In both of these series entrapment by facet joints was the pathological lesion and decompression produced good results.

There is increasing evidence (Macnab 1977) that "arthritis" of the facet joints is a common cause of backache and sciatica in patients over 50 years of age, prolapse of an intervertebral disc being more often seen in younger patients. Macnab has also described the pathological lesions involved. The cause of symptoms in most of the patients attending the Problem Back Unit at the Royal National Orthopaedic Hospital has been "bony" entrapment of the lumbar nerve root in the root canal, rather than prolapse of an intervertebral disc. An operative technique has been developed which allows decompression of the lateral part of the root canal by means of a partial undercutting facetectomy, while preserving stability of the spine and the depth of the spinal canal. In an attempt to define the clinical syndrome and to assess the results, the first 78 patients treated by this operation have been assessed independently (CJMG and JRJ), the operations having been performed or supervised by one of the two senior authors (EOK and MFS).

\section{MATERIAL AND METHODS}

The series included 42 men and 36 women. Symptoms had been present for between two months and 40 years (mean 10.6 years) and the age of the patients at the time of operation ranged from 23 to 75 years with a mean of 44.8 years. All patients had received conservative treatment which included analgesia, bed rest, physiotherapy, manipulations, spinal supports and epidural injections before they were referred to the Problem Back Unit. Twenty-eight of the patients (36 per cent) had previously undergone operations on the spine; 25 of these were for prolapse of an intervertebral disc, and three for spinal fusion. Symptoms had not been significantly relieved in any of these patients. The follow-up ranged from one to five years with a mean of 2.5 years.

Each patient was assessed before operation with particular reference to symptoms, signs and functional disability. Twenty-three patients (29 per cent) gave a history of injury before the onset of their spinal symptoms. The symptoms of which the patients complained are summarised in Table I. The most common presenting symptoms were low backache and

C. J. M. Getty, FRCS, Senior Orthopaedic Registrar, St Bartholomew's Hospital, West Smithfield, London EC1A 7BE, England. J. R. Johnson, FRCS, Senior Orthopaedic Registrar, University College Hospital, Gower Street, London WC1E 6AU, England. E. O'G. Kirwan, FRCS, Consultant Orthopaedic Surgeon $\{$ Royal National Orthopaedic Hospital,

M. F. Sullivan, FRCS, Consultant Orthopaedic Surgeon $\} 234$ Great Portland Street, London W1N 6AD, England.

Requests for reprints should be sent to Mr C. J. M. Getty, 5 Avon Way, Tavistock Road, South Woodford, London E18, England. (c) 1981 British Editorial Society of Bone and Joint Surgery 0301-620X/81/3068-0330\$2.00 
pain in the leg which was defined as pain extending beyond the knee (Macnab 1977). This was present in 75 patients ( 96 per cent) although 65 of them also had low backache. A history of claudication was reported by 13 patients (17 per cent).

The signs before operation are summarised in Table II. The most common neurological abnormality was a motor deficit, which was found in nearly half of the patients. Straight leg raising was significantly reduced in

Table I. Symptoms before operation in 78 patients with bony entrapment of lumbar nerve roots

\begin{tabular}{|l|cc|}
\hline \multicolumn{1}{|c|}{ Symptoms } & Number & Per cent \\
\hline Low back and leg pain & 65 & 83 \\
Leg pain & 10 & 13 \\
Low backache & 3 & 4 \\
(with abnormal neurological signs) & 45 & 58 \\
$\begin{array}{l}\text { Numbness and/or paraesthesiae radiating } \\
\text { thigh-calf-foot }\end{array}$ & 14 & 18 \\
$\begin{array}{l}\text { Weakness of the legs } \\
\text { Claudication }\end{array}$ & 13 & 17 \\
\hline
\end{tabular}

Table II. Signs before operation in 78 patients with bony entrapment of the lumbar nerve roots

\begin{tabular}{|l|cc|}
\hline \multicolumn{1}{|c|}{ Physical signs } & Number Per cent \\
\hline $\begin{array}{l}\text { Spinal movement reduced by at least } \\
\text { one-third in one or more directions }\end{array}$ & 55 & 71 \\
$\begin{array}{l}\text { Motor deficit shown by weakness and wast- } \\
\text { ing (L4 nerve root in 0; L5 in 26; S1 in 13) }\end{array}$ & 38 & 49 \\
Absent reflex (knee 3; ankle 30) & 33 & 42 \\
$\begin{array}{l}\text { Sensory deficit -impairment of sensation to } \\
\text { light touch and pin-prick. } \\
\text { (L4 dermatome in 1; L5 in 20; S1 in 10) }\end{array}$ & 30 & 38 \\
Straight leg raise of less than 30 degrees & 23 & 29 \\
\hline
\end{tabular}

only 23 patients ( 29 per cent). No significant differences were found between the patients who had previously undergone operation, and those who had been treated conservatively.

Routine haematological and biochemical investigations were carried out on all patients and were essentially normal. All patients had radiographs of the lumbar spine and a radiculogram or myelogram. Electromyographic studies were not carried out as a routine during the period of this review, and only eight patients, at the end of the period reviewed, had this investigation.

\section{INDICATIONS FOR OPERATION}

The recognition of arthritis of a facet joint as a cause of nerve root entrapment in the older patient, producing the clinical picture which has been outlined, has led to the development of a technique of partial undercutting facetectomy. The main benefit of this operation in these patients is to relieve pain of "root" origin. There is a variable effect on backache. This is to be expected since osteotomy of one facet joint at the site of root entrapment is unlikely to affect low back pain, when usually several levels are affected by degenerative change. Patients are therefore firmly told before operation that the procedure is designed to relieve symptoms in the leg, and that any reduction of backache is a bonus. The operation is not advised unless symptoms or signs in the leg are the predominant feature.

During the period of this study, clinical assessment in the light of an awareness of the possible pathological changes has been the basis of a decision to operate. This remains the main indication for operation although, as discussed later, the accuracy of diagnosis has been improved by the introduction of electromyographic studies.

The clinical indications are therefore continual or intermittent pain extending below the knee, with significant functional disability after the failure of conservative treatment, and a progressive neurological deficit in a patient suffering from backache and degenerative changes. Additional indications may arise during other operations. This method of undercutting facetectomy may be used in patients with central spinal stenosis to provide lateral decompression. Provided that the surgeon is satisfied that he is exploring the correct level, negative findings at operation for a prolapse of an intervertebral disc may be followed by an undercutting facetectomy which will expose the lateral part of the root canal and thus reveal possible bony entrapment.

\section{TECHNIQUE OF OPERATION}

Operations were carried out under general anaesthesia, with endotracheal intubation and muscle relaxation. The patient was prone on a spinal mattress, with the table broken.

A longitudinal incision is made alongside, but not directly over, the spinous processes. Fascia is divided with diathermy and the small muscles of the spine with scissors. In patients undergoing operation for the first time, a Cobb's elevator is used to strip muscle from the laminae, since this is less destructive to the periosteum of the laminae and the capsules of the facet joints. In patients who have had previous operations an osteotome is usually needed to strip muscle and scar tissue from the laminae. The sacrum is identified in all cases and meticulous haemostasis is maintained.

The spinal canal is then opened by a laminotomy fenestration (Fig. 1) at the level of the nerve root which has been indicated by clinical examination and investigation. Any lesion found within the canal is dealt with and the exploration is then carried laterally. The width of the pars interarticularis and especially its outer border is carefully defined, using a Watson Cheyne dissector. A 
bony dimple that is situated medially on the pars interarticularis is located and removed (Fig. 2). This opens part of the roof of the root canal. The nerve root, which may now be visible, is identified (Fig. 3) and the direction of the root canal is defined by gentle probing. surface of the superior articular process of the lower vertebra is reached, the osteotome is twisted to free the osteotomised fragment which is then eased out with a rongeur. At no stage in this operation should the fragments be forcibly pulled out or damage may be done

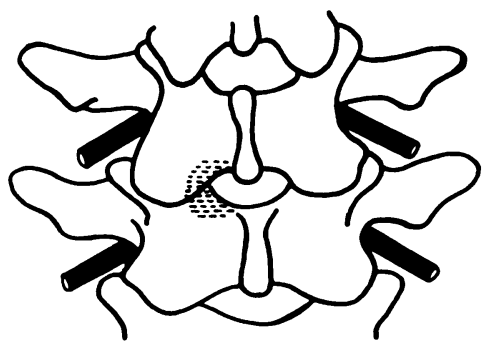

Fig. 1

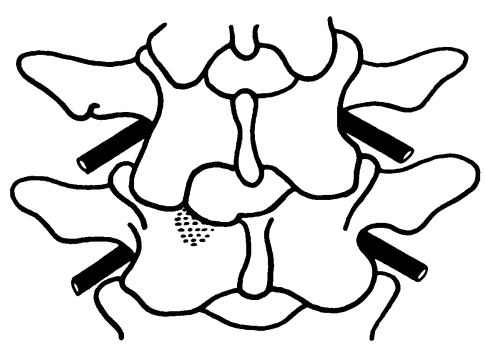

Fig. 2

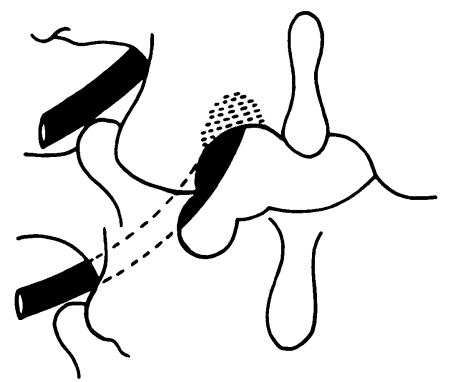

Fig. 3

Diagrams to show the surgical exposure for partial undercutting facetectomy. Figure 1-Bone removed in fenestration. Figure 2-Site of dimple in pars interarticularis. Figure 3-Removal of this dimple may expose the nerve root. Removal of more bone from the lamina of the upper vertebra (hatched area) may be needed to expose the origin of the root from the dural sac.

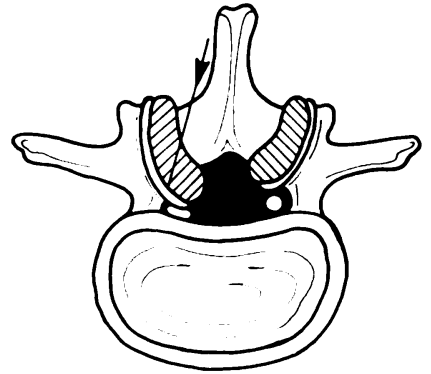

Fig. 4

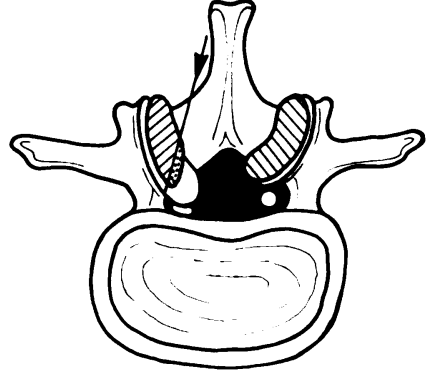

Fig. 5

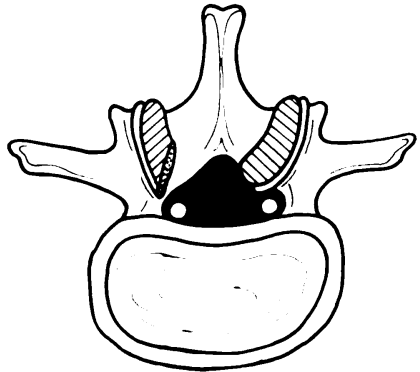

Fig. 6

Diagrams of cross-sections at the level of facetectomy. The hatched area is the inferior articular process of the upper vertebra and the trapped root is seen below the facet joint. Figure 4-The direction of the initial cut through the inferior articular facet. Figure $5-$ After removal of part of this facet. Figure 6-Completion of partial undercutting facetectomy.

Every attempt is made to see the root, but this is not always possible at this stage because subluxation and overgrowth of the facets may have hidden it from view. The nerve root must also be identified at its origin from the dural sac and this may require the removal of more bone from the lamina of the vertebra above the fenestration (Fig. 3).

The root canal is then decompressed using a 10 -millimetre osteotome which is advanced in an oblique direction, as indicated in Figure 4. The initial cut is made in the line of the nerve root. This is roughly parallel to the longitudinal axis of the spinal canal where the root passes under the facet joint before turning outwards below the pedicle. In this manner possible damage to the nerve root is minimised and if possible a MacDonald dissector is interposed between root and facet to provide additional safety. The osteotome is advanced with the percussion effect of rapid light blows in order to reduce further the risk of sudden uncontrolled advance. The use of a Kerrison's rongeur or a similar instrument in this narrow space is positively dangerous.

The initial osteotomy is obliquely through the inferior articular process of the upper vertebra at the level of decompression (Fig. 5). When the articular to the underlying nerve.

The osteotome is now advanced through that part of the superior articular process of the lower vertebra which is causing compression and this bone is extracted in the same careful manner (Fig. 6). The lateral attachments of the ligamentum flavum are removed with this portion of the bone, sharp dissection being used when it is necessary. It is important that the whole length of the facetal joint complex in a cephalocaudal direction is adequately decompressed. The removal of more bone from the lamina of the uppermost vertebra may be necessary to give access to the uppermost part of the facet joints. When hypertrophy and subluxation of the facets hide the nerve root, osteotomy is performed in the same way (Fig. 7). Provided that the root is identified where it arises from the dural sac and the described precautions are taken, the root will not be damaged. There have been, as yet, no such problems in patients operated on in this Unit.

At the end of the procedure the nerve root should lie freely through the root canal from its origin at the dural sac to its passage out through the intervertebral foramen. If it is seen to be kinked around the pedicle it is necessary to remove a layer of bone with an osteotome. 
A nerve root may be trapped by bone at two levels, and it is sometimes necessary to undercut the facet joints at both levels, which may require hemilaminectomy.

In the absence of a lesion-either centrally or laterally at the level explored it is necessary to consider

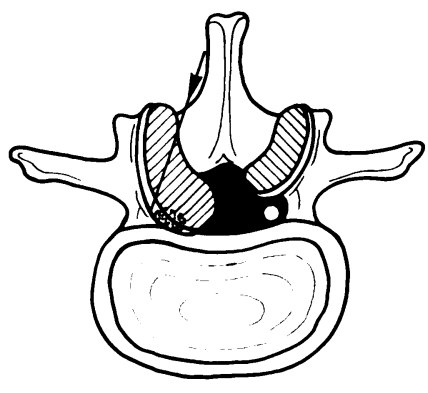

Fig. 7

Diagram to show that a nerve root may be hidden behind a hypertrophic facet joint.

exploration at other levels. This will also be needed if there is clinical evidence of involvement of more than one root.

There is often a small bulge due to an old degenerate disc lesion, though this may be represented only by a bony ridge. We do not usually operate on the disc unless partial facetectomy has failed to provide an adequate decompression, but careful search and clearance will be required in the presence of a sequestrated disc lesion.

This technique preserves stability since the facet joints are not totally destroyed and the pars interarticularis is preserved. Complete facetectomy has not been necessary in this series. In six patients early in the series, spinal fusions were done at the time of decompression. An additional advantage of partial facetectomy is that the tented shape of the spinal canal is preserved.

In most of our patients Sterispon was placed over the dura at the site of fenestration, in an attempt to prevent the formation of a laminectomy membrane (LaRocca and Macnab 1974), but a free fat graft is now used.

After operation patients are nursed supine for six hours. Log-rolling movements and straight leg raising are started as soon as possible after this. The patients are allowed to stand and walk as soon as they have control of their spine, provided that their temperature is normal and their wound is satisfactory. Patients return home 5 to 10 days after operation, when they are reasonably mobile, and return to work as soon as they are comfortable. They are carefully instructed in the care of their back.

\section{RESULTS}

All patients were reviewed personally. A comparison was made of symptoms, signs and disability before and after operation. The criteria for assessment after operation are shown in Table III.

Three patients showed radiographic evidence of abnormal segmentation in that all had four lumbar vertebrae. No significant correlation was found between asymmetry of the facets (Brailsford 1929) and the side, level or number of nerve roots involved. Radiological changes of degenerative disease (Macnab 1977) were seen in all but three patients.

Myelography or radiculography suggested a prolapsed disc at the level of root entrapment seen at operation in 52 per cent of patients. In 41 per cent there was a suggestion of disc prolapse at a different level than that of entrapment at operation. Only seven per cent had normal contrast studies. Failure of filling of the root sheath was seen in the radiculogram in some patients, but this was not of sufficient degree to be diagnostic of either bony entrapment or of disc prolapse.

The cause of nerve root symptoms and signs in all patients was degenerative change in the posterior joint complex, leading to either hypertrophy of the superior articular facet compressing the root against the vertebral body, or subluxation of the facet joints with or without osteophyte formation. In most patients both causes were present, sometimes at more than one level. A small bulge in the disc was often present and was removed at the same operation in 24 patients ( 31 per cent).

The appearances of the nerve roots varied, with no uniformity to characterise this group of patients. Compression was always obvious and in many cases there was a small indentation at the site of maximal compression. Adhesions were not common but little or no epidural fat was seen in the lateral recess.

The decompression was unilateral in 65 patients, in whom one root at L4 level, 24 at L5, 20 at S1 and 19 at both L5 and S1 were operated on. In one patient conjoined L5 and S1 roots were decompressed on one side. Thirteen patients had bilateral decompression at either L5 or S1 levels or both.

There were no operative complications. Four patients developed a deep vein thrombosis after operation, all of whom responded to anticoagulants. Urinary retention occurred in three patients but all recovered when catheters were removed and they were up and about. There were no deep wound infections.

The results of operation are shown in Table IV. There was no significant correlation between the result in the previously operated group and the number of previous laminectomies. The symptom most frequently relieved was pain in the leg. Sixty per cent of patients

Table III. Criteria for assessment of results

\begin{tabular}{|l|l|}
\hline $\begin{array}{l}\text { Relief of leg pain. Continued in previous occupation or } \\
\text { with previous hobbies }\end{array}$ & Good \\
\hline $\begin{array}{l}\text { Partial relief of leg pain with or without temporary } \\
\text { exacerbation after heavy work. Continued in previous } \\
\text { occupation and hobbies, but has needed periods off work }\end{array}$ & Fair \\
\hline $\begin{array}{l}\text { No relief of leg pain. Unemployed, or changed } \\
\text { occupation to light work }\end{array}$ & Poor \\
\hline
\end{tabular}


described relief within six weeks, and in all but four this has been maintained. At review 38 patients complained of low backache, most of these having had pain before operation. Eighteen of these 38 patients had, however, gained relief of leg pain as a result of treatment (Table exploration dense fibrosis was a common feature. Of the remaining five patients, one was an alcoholic, one a hysteric, and one had marked functional overlay. The mean duration of symptoms before operation in the poor group was 12.5 years compared with 9.5 years in

Table IV. Results of nerve root decompression by partial facetectomy

\begin{tabular}{|l|c|cc|cc|cc|}
\hline & \multirow{2}{*}{ Group } & \multicolumn{5}{c|}{ Results } \\
\cline { 3 - 8 } & \multirow{2}{*}{$\begin{array}{c}\text { Number of } \\
\text { patients }\end{array}$} & \multicolumn{2}{|c|}{ Good } & \multicolumn{2}{c|}{ Fair } & \multicolumn{2}{c|}{ Poor } \\
\cline { 3 - 8 } & Number & Per cent & Number Per cent & Number Per cent \\
\hline Primary facetectomy & 50 & 33 & 66 & 12 & 24 & 5 & 10 \\
Previous disc excision & 25 & 12 & & 6 & & 7 & \\
Previous spinal fusion & 3 & 1 & & 2 & & 0 & 12 \\
\hline Total & 78 & 46 & 59 & 20 & 26 & 12 \\
\hline
\end{tabular}

V). Poor results were characterised by persistent low backache and leg pain and in none of these patients was there any relief of symptoms in the first six weeks after operation.

The findings on physical examination after treatment are shown in Table VI. Eight patients showed reduced spinal movements. One patient developed motor and reflex deficit of L4 after operation and in another patient reflex and sensory deficit of S1 had appeared by the time of review. These patients were all in the poor group.

Of the 12 patients who were graded as poor, seven had undergone previous laminectomy. At re-

Table V. Comparison of symptoms in the whole series before and after decompression of the nerve roots

\begin{tabular}{|l|cc|cc|}
\hline \multirow{2}{*}{\multicolumn{1}{|c|}{ Symptom }} & \multicolumn{2}{c|}{ Before operation } & \multicolumn{2}{c|}{ After operation } \\
\cline { 2 - 5 } & Number & Per cent & Number & Per cent \\
\hline Pain below the knee & 75 & 96 & 19 & 24 \\
Low backache & 68 & 87 & 38 & 49 \\
Claudication & 13 & 17 & 5 & 6 \\
\hline
\end{tabular}

Table VI. Comparison of physical signs before and after decompression of the nerve roots

\begin{tabular}{|l|cc|cc|}
\hline \multirow{2}{*}{\multicolumn{1}{|c|}{ Physical signs }} & \multicolumn{2}{c|}{ Before operation } & \multicolumn{2}{c|}{ After operation } \\
\cline { 2 - 5 } & Number & Per cent & Number & Per cent \\
\hline $\begin{array}{l}\text { Reduced spinal } \\
\text { movements }\end{array}$ & 55 & 71 & 16 & 21 \\
Motor deficit & 38 & 49 & 18 & 23 \\
Reflex deficit & 33 & 42 & 33 & 42 \\
Sensory deficit & 30 & 38 & 20 & 26 \\
$\begin{array}{l}\text { Straight leg raise of } \\
\text { less than 30 degrees }\end{array}$ & 23 & 29 & 5 & 6 \\
\hline
\end{tabular}

the good group and this difference in duration of symptoms is statistically significant at $P<0.05$ level.

\section{DISCUSSION}

This study of the clinical features produced by bony entrapment of lumbar nerve roots in a spinal canal of normal dimensions has shown several interesting features. O'Connell (1951), in a review of 500 disc excisions, reported that 73 per cent of his patients underwent operation between the ages of 20 and 40 years, while 77 per cent had suffered symptoms for less than five years. The mean age at operation in this series was 44.8 years and the mean period from onset of symptoms to operation was 10.6 years. This long period probably reflects the natural history of degenerative change in the spine and is in keeping with the finding that while leg pain was the predominant symptom, most patients also gave a long history of backache. Paine and Haung (1972) have shown that most patients with prolapse of an intervertebral disc develop backache and sciatica simultaneously. Other factors contributing to this long period in the present series are delay in establishment of the diagnosis and in referral to a specialist centre. Reduction in delay should be possible with increasing awareness of this syndrome and this may provide better results since prolongation of nerve root entrapment may lead to irreversible damage. It is of interest that only 17 per cent of the patients had a definite history of claudication.

Most patients had some reduction in spinal mobility, but the incidence and extent of this was less than that reported by O'Connell (1951) in patients with prolapse of intervertebral discs. In contrast to the findings of Epstein et al. (1972) and of Choudhury and Taylor (1977) but in agreement with Macnab (1977), a positive straight leg raising test was not commonly found. Neurological abnormality was less common than in O'Connell's series, although as in disc lesions a motor deficit was the most common finding. The series 
confirmed Macnab's observation (1977) that more than one root may be involved by bony entrapment. This was clinically evident in 31 per cent of our patients.

Investigations available in this series have had limited value in demonstrating pathological lesions, but it is considered that contrast studies should be carried out in all patients before operation on the spine. The value of these studies in this series is difficult to assess, in that about one-third were myelograms using an oily contrast medium, and over a third of the patients had previously undergone contrast studies and operative treatment.

The clinical history and examination together with awareness of the syndrome are most important. Radiculography may be little help or even cause confusion because the lesion is too lateral to be shown by the contrast medium. Electromyographic studies more recently have been of considerable value in demonstrating whether leg pain is of root origin, and in improving the accuracy of diagnosis of the level of the involved root (Leyshon, Kirwan and Wynn Parry 1980).

Various techniques of facetectomy have been described (Putti 1927; Briggs and Krause 1945; Schatzker and Pennal 1968; Shenkin and Hash 1976; Bowen, Shannon and Kirkaldy-Willis 1978). The technique that has been developed differs from these. The difference between our method and that of Bowen et al. (1978) is that we believe that it is important to remove the ligamentum flavum in order to see the lateral recess clearly, and because it may contribute to compression in the root canal. The technique is a partial facetectomy and preserves spinal stability. The pars interarticularis is preserved and no patient in this series has developed spondylolisthesis acquisita.

Fifty-nine per cent of the patients achieved a good result but 85 per cent of patients were satisfied with the outcome of their treatment (Table III). The incidence of low back pain in the good group fell from 89 per cent to 33 per cent, and was described as an ache by most patients.

The high success rate in patients who had previously undergone spinal operations is due to the fact that most of them had previously had a negative exploration of the spine and excision of a minimal bulge of an intervertebral disc. Hardly any of these patients had gained relief of their leg pain after their original operation. The true cause of symptoms had not been appreciated so that re-operation was carried out in a previously unexplored area. Bony entrapment should always be suspected when a significant prolapse of the disc is not found at laminectomy and the root should be traced outwards in its canal.

A striking feature of the successful results in this series was the rapid and lasting relief of leg pain and this is a useful early prognostic sign. It is of interest that 30 patients also gained relief of their backache.

The results show that patients with bony entrapment of a lumbar nerve root, in the presence of a spinal canal of normal dimensions, may present from the fourth decade onwards with a long history of backache and the later development of leg pain, which is usually unilateral. Physical examination is characterised by some reduction in spinal movements with involvement of motor function in approximately half of the cases. Straight leg raising is reduced in only a third of the patients. Electromyography, which may demonstrate a functional defect in nerve conduction, will probably prove to be the most useful single aid to diagnosis. Computerised axial tomography in patients who have not had previous surgical treatment has been shown to be of limited value (Getty et al. 1981). This method of partial undercutting facetectomy has eliminated the need to carry out a complete facetectomy for a degenerative change compromising a nerve root.

The authors wish to thank Sister Hunter and the Medical Records Department for the organisation of clinics; and Mr Terry Davis and the Photographic Department of the Royal National Orthopaedic Hospital for the diagrams.

\section{REFERENCES}

Bowen V, Shannon R, Kirkaldy-Willis WH. Lumbar spinal stenosis. Child's Brain 1978;4:257-77.

Brailsford JF. Deformities of the lumbosacral region of the spine. Br J Surg 1929;16:562-627.

Briggs H, Krause J. The intervertebral foraminotomy for relief of sciatic pain. J Bone Joint Surg [Am] 1945;27:475-8.

Choudhury AR, Taylor JC. Occult lumbar spinal stenosis. J Neurol Neurosurg Psychiat 1977;40:506-10.

Epstein JA, Epstein BS, Rosenthal AD, Carras R, Lavine LS. Sciatica caused by nerve root entrapment in the lateral recess: the superior facet syndrome. J Neurosurg 1972;36:584-9.

Getty CJM, Dixon AK, Young A, Lettin AWF. The role of computerised tomography in degenerative lumbar spine disease-A prospective trial. $J$ Bone Joint Surg [Br] 1981;63-B: In press.

LaRocca H, Macnab I. The laminectomy membrane. J Bone Joint Surg [Br] 1974;56-B:545-50.

Leyshon A, Kirwan EO'G, Wynn Parry CB. Is it nerve root pain? J Bone Joint Surg [Br] 1980;62-B:119.

Macnab I. Backache. Baltimore: Williams and Wilkins Co, 1977.

Mixter WJ, Barr JS. Rupture of the intervertebral disc with involvement of the spinal canal. N Engl J Med 1934;211:210-15.

O'Connell JEA. Protrusions of the lumbar intervertebral discs: a clinical review based on 500 cases treated by excision of the protrusion. $J$ Bone Joint Surg [Br] 1951;33-B:8-30.

Paine KWE, Haung PWH. Lumbar disc syndrome. J Neurosurg 1972;37:75-82.

Putti V. New conceptions in the pathogenesis of sciatic pain. Lancet 1927;ii:53-60.

Schatzker J, Pennal GF. Spinal stenosis, a cause of cauda equina compression. J Bone Joint Surg [Br] 1968;50-B:606-18.

Shenkin HA, Hash CJ. A new approach to the surgical treatment of lumbar spondylosis. $J$ Neurosurg 1976;44:148-55. 